\title{
Operational auditing versus traditional method: A comparative investigation
}

\author{
Reza Tehrani $^{\mathrm{a}}$ and Amir Hasan Ghorbani ${ }^{\mathrm{b}^{*}}$
}

${ }^{a}$ Associate professor, Department of finance, University of Tehran, Tehran, Iran

${ }^{b}$ M.A student of financial management, University of Tehran, Tehran, Iran

\section{H R O N I C L E}

\section{Article history:}

Received January 16, 2013

Received in revised format

22 April 2013

Accepted 28 April 2013

Available online

April 302013

Keywords:

Operational auditing

Financial efficiency

Economic saving

\section{A B S T R A C T}

Operational auditing is one of the management consultancy services whose significance is on the rise day by day. This approach is, clearly, a systematic and methodical process used to evaluate economic savings of financial processes in organizations and the results of the evaluations are reported to interested people along with some comments to improve operational processes. Accordingly, it appears that the proper employment of the existing rationale in operational auditing can be a significant step towards the improvement of financial efficiency in Iranian public and private banking sector. This paper studies the effects of operational auditing on the improvement of economic saving of financial processes in Iranian private banks compared with traditional approaches where the operations are based on financial statements. The population of this survey includes 15 private and public Iranian banks and the proposed study selects 78 branches, randomly. The Cronbach alpha was used to test the reliability a questionnaire employed to collect the needed data in this study. The results obtained by SPSS Software indicated that the reliability of the instruments $\backslash$ ranged between 0.752 and 0.867 , suggesting an acceptable level of the reliability for the questionnaire. Besides, content validity was used to confirm the validity of the instrument. The results of the study indicated that the operational auditing as a useful approach influencing the financial efficiency of public and private banks has significantly transformed the traditional thinking in the field of management auditing. The operational auditing has a number of significant advantages including a better method of controlling financial operations within Iranian banks, efficient planning in the future, facilitating efficient, appropriate, and accurate management decision making, and sound evaluation of managers' financial operations.

\section{Introduction}

All managers in economic organizations, industrial and productive units, and service institutions normally attempt to implement various sources such as work force, capital, materials, energy and information. The existence of appropriate organizational structures, efficient executive methods, safe equipment and instruments, balanced workspace, and capable human resources are among necessary requirements, which need to be taken into account by managers to achieve optimal organizational productivity.

*Corresponding author.

E-mail addresses: ahgh123@yahoo.com (A. H. Ghorbani) 
Accordingly, the optimal and efficient use of utilities, capacities, capitals, resources, and opportunities is stated as a standard and fundamental definition of the term "organization productivity" since this definition, while being comprehensive, clearly and simply indicates the concept of "productivity" among various economic, industrial-productive, and service organizations. Based on the definition provided, the improvement of "organization productivity" within the general structure of an organization may be regarded as one of the most important management objectives so that any attempt to instill the culture of "productivity improvement" in all organizational dimensions is totally justified and rational (Arbab Soleimani \& Nafari, 2003).

In addition, it is clear that all organizations founded in different commercial environments aim to achieve specific goals. In this line, management knowledge is seen as an instrument to employ the existing resources efficiently to achieve defined organizational objectives. A manager is supposed to plan, organize, and control organizational operations to achieve the highest organizational interest possible. In today's world, accountable and pioneer managers are always trying to be completely assured of fulfillment of their obligations through accurate monitoring and evaluation so that to keep themselves prepared and strong in dealing with organizational problems and issues by receiving continuous feedback. Accordingly, an organization manager's success in optimal use of the available resources can be considered as one of the effective factors in predicting the organization's success in the achievement of the defined organizational objectives (Supreme Audit Court, 2008, 2009).

In order to achieve a successful management system within the organization corresponding to each active and efficient part of organizational structure, the provision of accurate management information can be regarded as an important step in this process. Besides, one of the key factors in business fate of all organizations is, in fact, the financial system within the organization. Equipping the organization management with an inclusive set of accurate financial information will be a useful action towards creation of a successful management and thus a successful organization in the process of the achievement of predetermined organizational goals (Alvani, 2002).

There is an increasing complexity of societies and their specific issues as well as the conflict in the information providers' objectives with regard to financial system performance. In addition, there are some concerns on the objectives of the users of the financial system information, especially the organization managers who are very interested in acquiring a complete knowledge on the financial system performance. Therefore, there is an urgent need for the existence of an independent part within the financial system as "Financial Auditing Unit". More clearly, given the complexity of financial issues in public and private organizations, in order to provide a clear and complete picture of the reality of the organization financial matters, it is essential to employ people who possess competence and professional honesty to make available appropriately the financial information needed by the management, systematically. In today's world, all business managers in the public and private sectors need to have the access to some organizational financial operations in addition to existing financial information. Operational auditing is in fact one of the most essential management consultancy services, which gains more attentions. Operational auditing has been defined by the Operational Auditing Committee of the Auditing Organization under "Introduction to Operational Auditing" as follows:

"Operational auditing refers to a process of regular and systematic evaluation of the effectiveness, the efficiency, and the economic saving of the organization activities so that the results of such evaluation along with practical suggestions are reported to authorized persons in order to improve organization operations will be provided". (The Technical Committee of the Auditing Organization, 2000: Auditing Standards).

Accordingly, the three main components including "effectiveness", "efficiency" and "economic saving" play essential role in describing the nature of the "operational auditing" so that a sound awareness of these components help us gain a deep understanding of the concept of "operational accounting". As a result, the present study focuses on the concept of "economic saving" based on the following definition : 
"Economic saving, clearly, refers to making efforts to minimize the costs of obtaining organizational resources and using them while maintaining their quality" (Auditor Journal, 2002: Introduction to Operational Auditing).

\subsection{Objectives of the operational auditing}

Operational auditing is, indeed, a clear example of management consultancy services, which may even have some common characteristics with the financial statements auditing. This type of auditing involves a systematic review of an organization's activities or a certain part of its activities to achieve specific objectives. As a result, general objectives of the operational auditing are summarized as follows:

\subsubsection{Performance evaluation}

Operational auditing involves evaluating the performance of all business/economic entities. In this connection, performance evaluation means to compare appropriate techniques to do the organization activities such as policies, standards, quantitative objectives, and other criteria implemented for proper measurements with the goals determined by the management or the contracting party.

\subsubsection{Identification of opportunities to improve the operations}

Clearly, the improvement of operations is associated with enhancement of economy saving, efficiency, and effectiveness, or a combination of these three basic factors. Operational auditing determine improvement opportunities for comprehensive analysis, interviews with individuals including firms' insiders or outsiders, observation of necessary operations, investigation of the current and past reports, transactions review, industry standards, the employment of professional judgment based on experience, or other appropriate tools.

\subsubsection{Suggestions for improvement of the operation or the need for further actions or investigations}

It is evident that the kind, nature and scope of recommendations expressed in operational auditing process are totally different and in several cases, the auditor may express special recommendations. In other cases, more investigation may be essential not in the scope forecasted in the contract. In such cases, the auditor provides the necessary reasons for more actions and investigation.

\subsubsection{Operational auditing service providers}

In today's economy, auditors are often requested to evaluate the financial operations of a given organization. Although the provision of such services by auditors is not a new, there is a growing trend on demand for these kinds of services with greater emphasis on the economic saving of financial operations. Considering abnormalities and undesirable phenomena such as the following cases in most Iranian financial-credit organizations, more specifically financial-credit firms associated with public/ government sector, one can easily conclude the issue of productivity especially economic saving in these organizations are widely being ignored .

-The lack of successful achievement of organizational objectives with minimum cost,

-Unavailability of useful techniques to reach organizational objectives through the use of minimal resources to earn the maximum efficiency/return,

-Non-performance of financial affairs based on a proper and decent behavior,

-Failure to obtain the maximum efficiency/return for a given data,

-Failure to increase production with the same data,

-Inappropriate and extensive use of manual techniques, 
-The existence of the extensive and useless paperwork,

-The widespread use of inefficient operational systems and procedures,

-The existence of a hierarchies or complex communication patterns in the organization,

-Extensive duplication within the organization,

-Unnecessary work processes and large-scale parallel works,

Clearly, more consistent and organized efforts are not taken to remedy the situation and more appropriate and efficient methods are not implemented to get feedback through the implementation of a scientific and practical approach to audit the organization's financial activities in the current financial system .

Based on what we have stated earlier with regard to the "operational auditing", it appears that the proper implementation of the existing logic in operational auditing would be an effective step in improving the efficiency of financial-credit institutions active in the public sector. However, the author of the present study, based on the system thinking, believes that that Iran's "environmental conditions and restrictions" should be stated as a set of influential factors influencing the achievement or non-achievement of planned or unplanned objectives. Perhaps it is not possible sometimes to implement a system design for a given environment in other operational environments or to expect similar results because of special environmental parameters. Therefore, to introduce and implement operational auditing in large-scale Iranian financial-credit institutions in the public sector, the first essential step seems to be the provision of clear evidence based on an independent study of the success of few firms that have already employed operational auditing. This helps to have sufficient evidence to answer a fundamental question of whether the use of operational auditing compared with traditional methods focused on the preparation and review of financial statements could influence the efficiency of the financial system of Iranian financial-credit institutions in the public sector or not significantly or not. In recent years, the focus and the scope of some auditing methods for public and private sector has undergone many changes and since the financial statements alone cannot meet the management informational requirements, managers in the public and private sectors look for obtaining more information to evaluate the quality and the progress of operations. Therefore, there is an urgent need for the existence of operational auditing techniques to assess economic saving of financial operations. These days, successful managers in various independent organizations have clear evidence about the existence of problems within their organizations and they believe that an impartial investigation and the provision of the resulting suggestions can bring about numerous benefits for their organizations. Analyzing the causes of managers' growing demand to receive operational auditing services indicates that the following rationales provide good basis for the employment of operational auditing :

-Managers are motivated to pay more attention to put into practice economic saving in business units .

-Enhancement of independent auditors' experience in diagnosing and discovering realities associated with financial auditing and management consulting and providing manages with guidelines if needed .

As was mentioned earlier, unfortunately due to lack of adequate understanding about the rationality behind the use of operational auditing in Iranian financial-credit institutions particularly those active in the public sector, the operational auditing approach in financial-credit institutions in the public sector has not received significant attention. On the other hand, since the country's financial resources in both the private and the public sectors belong to the society's general wealth of society; incorrect and unplanned implementation of such resources and wasting them cannot be considered a wise action at all. However, despite all previous achievements, what is important in this regard is that based on "system thinking", it is always necessary to consider "environmental conditions and constraints" as important factors influencing the achievement or non-achievement of intended outcomes. More clearly, perhaps it is not possible sometimes to use a system designed for a given 
environment in other operational environments or to expect similar results because of special environmental parameters. Consequently, to introduce and implement operational auditing at a large scale in Iranian financial-credit institutions in the public sector, the first is to have some evidence based on an independent study on the success of few organizations. This would help us have scientific and practical evidence on how this method would work in Iran so that we could make plans and decisions based on these findings.

\section{The proposed study}

The primary objective of this study is, in particular, to assess the effects of operational auditing on the improvement of economic saving of financial processes in Iranian private banks compared to traditional approaches based on financial statements.

There are some other secondary objectives for the proposed study of this paper as follows,

- Analyzing the effectiveness of implementing operational auditing in maximizing defined (standard) economic savings by managers of financial systems in Iranian financial-credit institutions in the private sector with regard to the use of human resources needed for different financial operations compared with the traditional approaches based on the financial statements,

- Analyzing the effectiveness of using operational auditing in maximizing defined (standard) economic savings by managers of financial systems in Iranian financial-credit institutions in the private sector with regard to the use of financial resources needed for different financial operations compared with the traditional approaches based on the financial statements,

- Analyzing the effectiveness of using operational auditing in maximizing defined (standard) economic savings by managers of financial systems in Iranian financial-credit institutions in the private sector with regard to the implementation of equipment needed for various financial operations compared to the traditional approaches based on the financial statements.

\subsection{The main question of the survey}

Does the use of operational auditing have a significant influence on economic savings of financial systems in Iranian financial-credit institutions, given the current context, circumstances, and limitations?

\subsection{The secondary research questions}

- Does the use of operational auditing have a significant influence on maximizing defined (standard) economic savings by managers of financial systems in Iranian financial-credit institutions in the private sector with regard to the use of human resources needed for different financial operations, given the current context, circumstances, and limitations?

- Does the use of operational auditing have a significant influence on maximizing defined (standard) economic savings by managers of financial systems in Iranian financial-credit institutions in the private sector with regard to the use of financial resources needed for different financial operations, given the current context, circumstances, and limitations?

- Does the use of operational auditing have a significant influence on maximizing defined (standard) economic savings by managers of financial systems in Iranian financial-credit institutions in the private sector with regard to the use of equipment needed for different financial operations, given the current context, circumstances, and limitations?

\subsection{Research hypotheses}

The main hypothesis:

The use of operational auditing has a significant influence on economic savings of financial systems in Iranian financial-credit institutions, given the current context, circumstances, and limitations. 


\subsubsection{Research sub-hypotheses}

- The use of operational auditing has a significant influence on maximizing defined (standard) economic savings by managers of financial systems in Iranian financial-credit institutions in private sector with regard to the implementation of human resources needed for various financial operations, given the current context, circumstances, and limitations.

- The use of operational auditing has a significant influence on maximizing defined (standard) economic savings by managers of financial systems in Iranian financial-credit institutions in the private sector with regard to the use of financial resources needed for different financial operations, given the current context, circumstances, and limitations.

- The use of operational auditing has a significant influence on maximizing defined (standard) economic savings by managers of financial systems in Iranian financial-credit institutions in the private sector with regard to the implementation of equipment needed for various financial operations, given the current context, circumstances, and limitations.

\subsection{Research methodology}

The methodology implemented to perform the present study is described in form of the following four phases:

In the first phase of the study, abnormalities and the adverse events associated with the efficiency of the financial systems in financial-credit institutions within public and private sectors are investigated to provide a set of symptoms to understand the main problem under study. In fact, according to system thinking such symptoms can guild researchers to come up with a better understanding of the problem space and help them to find the appropriate solutions to the problem. Given the relative importance of the efficiency of financial systems within financial-credit institutions affiliated to public and private sectors and the restrictions on access to all of these institutions, the following financial-credit institutions/banks were selected as the population to collect the needed data in the present study:

Sepah Bank, Melli Bank, Saderat Bank, Tejarat Bank, Mellat Bank, Refah Karegaran Bank, Parsian Bank, Pasargad Bank, Eghtesad Novin Bank, Saman Bank, Kar Afarin Bank, Sarmayeh Bank, Ansar Bank, Ferdowsi Bank, and Ghavamin Bank.

In the second phase, in-person or non-person interviews were given to experts and elites ${ }^{1}$ about the problem under study to provide data for subsequent analysis. The third phase of the study addressed the content analysis of the information obtained through the interviews to develop a set of questions/items to be used in the questionnaires employed as instruments to collect the data. After the determination of variables needed to perform a deep analysis of the influence of operational auditing on improving the efficiency of the financial system within the institutions under study, a number of questionnaires were developed. Furthermore, the interviewees and the experts with profound knowledge on the problem were consulted in order to come up with a full understanding of the variables under study. These variables reflected the efficiency level of the financial systems in any of the organizations under study, which are, in fact, a representation of financial systems performance. Finally, the fourth phase of the study dealt with the final approval on the part of experts and elites in connection with the problem under study in order to validate the processes used.

\subsection{Population and sampling}

All higher experts in the field interviewed in the first stage of the study together with other top experts in the field of financial systems consulted in the second phase were selected as the population under study. In the first phase of study, a suitable sample was selected to perform the field analyses

\footnotetext{
${ }^{1}$ In this study, the terms expert or elite refer to a person who holds at least a M.A degree on financial and auditing sciences and has at minimum a 20 -year experience in this filed.
} 
through non-probability snow ball sampling. Accordingly, 22 experts selected through nonprobability sampling in non-persons interviews were asked to fill out open questionnaires. The obtained data were analyzed to the findings were used to develop a multi-item questionnaire. This sampling was considered as the pilot sampling with the sample size of 22 experts at the level of financial-credit institution affiliated to the private sector. The data collected from this pilot sample were used as a basis to determine the size and the members of the final sample.

Table 1

Pilot sampling and its properties

\begin{tabular}{ll}
\hline Pilot sampling & Properties \\
\hline Sampling nature & Non-probability sampling \\
The rationale for the approach taken in the sampling process & Snowball \\
The sample size & 22 Units \\
The method used to collect data & In-person and non-person interviews \\
Instruments & Open and closed questionnaires \\
\hline
\end{tabular}

In the second stage, simple cluster sampling has been employed to select an appropriate sample to perfume the needed field examinations. To put it more clearly, at this stage it was attempted to choose randomly a number of the experts in the field who were somehow associated with organization financial system for each institution as a cluster in this study. The selected samples were studied further to select the final sample. Meanwhile, the most important issue was deciding the number of experts for any institution under study through the following calculation process. Eq. (1) assumes that variables defined in the sample i.e. all items presented in the questionnaire follow normal probability distribution (Azar \& Momeni, 2002). Besides, since the sample selected for organizations under study were without placement, as a result, building upon the literature in the field the following equation was used to determine the size of the final sample:

$$
\begin{aligned}
& x \sim N\left(\mu, \frac{\sigma^{2}}{n}\right) \\
& n=\frac{n_{0}}{1+n_{0} / N}
\end{aligned}
$$

Accordingly; we come up with the following equation:

$$
n_{0}=\left(\frac{z}{r} \cdot \frac{s}{\mu}\right)^{2} \text {. }
$$

In Eq. (2), $z$ is a point on the horizontal axis of normal probability distribution that assumes different corresponding values for various probability values (under the curve area). The numerical value of $z$ for $\alpha=0.05$ is approximately chosen as equal to 2 . In Eq. (2), $\mu$ represents the mean of probability distribution for variables under study. In addition, $r$ is the upper limit of the relative error, which is $3 \%$ in the present study. It is clear that $\mathbf{N}$ shows the final size of each cluster whose value is approximately 10 based on the evidence presented in this study. To determine the size of the final sample, first the values of $S$ and $\mu$ were estimated based on pilot sampling. Then, the size of the final sample for each item in the questionnaire associated with each sample under study was determined based on the estimated values. Clearly, it is not possible to use the same sample size for all the items in the questionnaire. As a result, the minimum size of the final sample was chosen as the representative sample for each cluster. Accordingly, the size of final sample in the present study was determined as 78 sampling units, which include professionals, managers, and top experts who were active in financial systems of the organizations under investigation for the time period when the study was being conducted.

\section{Data analysis}

In each research project, the collected data are analyzed through stochastic models and inferential statistical principles within a statistical software environment. To do so, one-way ANOVA and 
dependent statistical tests (T-Student test) was employed by running SPSS Software to obtain the desired outputs in order to analyze the effects of operational auditing on the improvement of the efficiency of financial systems within the organizations under study.

Empirical evidence suggests that ordinal variables have the same function as the interval scales provided that the distances between categories are equal. As a result, most parametric statistical analyses such as mean comparison or one-way ANOVA can be used for ordinal variables. In other words, if a five-or-more-item ordinal Likert scale (from very low to very high or strongly disagree to strongly agree) used in a study, a coding procedure or numbers (1 to 5) can be used to perform a great number of statistical analyses.

The data obtained from the final sample, comprising a significant population of (top/middle, and low ranking) elites and experts, were analyzed to test the research hypotheses and, consequently, to determine effects of operational auditing on the efficiency of financial systems within the institutions/banks under study.

\section{Table 2}

Statistical test of research hypotheses

\begin{tabular}{lrrrrr}
\hline Random variables & Mean & SD & T Student & Sig. & df \\
\hline Effects of IS auditing to avoid intentional and human error & 4.5143 & 0.65849 & 20.167 & 0.00 & 77 \\
Degree of importance of operational index No. 2 & 4.5143 & 0.78108 & 17 & 0.00 & 77 \\
Degree of importance of operational index No. 3 & 4.3714 & 0.94202 & 12.76 & 0.00 & 77 \\
\hline
\end{tabular}

Based on studies accomplished it seems that the degree of importance of at least 3 which means the minimum moderate importance of the method under study can be considered as a reasonable basis for making judgments about the appropriateness or inappropriateness of each of the indicators defined for measuring the effects of operational auditing on the improvement of the efficiency of financial systems in Iranian private and public banks. In this study, we have tried to test each defined variable separately and, as can be seen from Table 2, the results of the statistical tests confirm the establishment of all defined parameters in this study.

Here we are interested in comparing the relative importance of all defined indicators to rank them. To do so, one-way ANOVA as a statistical approach to compare the mean scores for more than two populations. In other words, our goal is to compare the means for the importance of the defined indicators to provide a basis a basis for prioritizing these indicators.

$\left\{\mathrm{H}_{0}: \mu_{1}^{\mathrm{B}}=\mu_{2}^{\mathrm{B}}=\mu_{3}^{\mathrm{B}}\right.$

$\left\{\mathrm{H}_{1}:\right.$ Not $\mathrm{H}_{0}$

In the above equation, $\mu_{\mathrm{i}}^{\mathrm{B}}, \mathrm{i}=1,2,3$, represents the mean of the degree of importance for $i$ th indicator.

Table 3

Results of ANOVA for the indicators used in the study

\begin{tabular}{lccccc}
\hline Importance & Sum of Squares & d.f & Mean Square & F & Sig. \\
\hline Between Groups & 41.724 & 2 & 20.862 & 38.991 & .000 \\
Within Groups & 40.128 & 75 & 0.53504 & & \\
\hline Total & 143.796 & 77 & & \\
\hline
\end{tabular}

As shown in Table 3, there is no significant difference between operating indicators so that the effect of each indicators is not the same as for other indicators. Besides, the differences between factors/indicators were compared to rank the indicators under study. To do so, Tukey HSD Test and the confidence intervals were employed as shown in Table 4: 
Table 4

Results of Tukey Test

\begin{tabular}{|c|c|c|c|c|c|}
\hline \multicolumn{6}{|c|}{ Importance } \\
\hline \multirow{6}{*}{ Tukey HSD ${ }^{a}$} & V & $\mathrm{N}$ & & for alpha & \\
\hline & & & 1 & 2 & 3 \\
\hline & V1 & 78 & 3.6667 & & \\
\hline & V3 & 78 & 4.1000 & 4.1000 & \\
\hline & V2 & 78 & & 4.3667 & 4.3667 \\
\hline & Sig. & & 0.249 & .0467 & .0249 \\
\hline
\end{tabular}

Means for groups in homogeneous subsets are displayed.

a. Uses Harmonic Mean Sample Size $=78.000$.

As it can be seen, the following priorities are presented with regard to the ranking the importance of defined indicators to investigate the effects of operational auditing on economic savings of financial systems within the institutions/banks under study;

1. Maximizing the achievement of defined (standard) speed for various financial operations performed by managers of financial-credit institutions affiliated to the private sector in Iran in contrast to the traditional approaches based on the financial statements,

2. Maximizing the achievement of defined (standard) precision for various financial operations performed by managers of financial-credit institutions affiliated to the private sector in Iran in contrast to the traditional approaches based on the financial statements,

3. Enhancing the probability of achieving objectives defined by managers of financial-credit institutions affiliated to the private sector in Iran in contrast to the traditional approaches based on the financial statements.

\section{Results of the study}

The present study aimed to examine the effects of operational auditing on the improvement of economic saving of financial processes in Iranian private banks compared to traditional approaches based on financial statements. Accordingly, the following general results were observed by the examination of the research hypotheses:

- The employment of operational auditing has a significant influence on maximizing defined (standard) economic savings by managers of financial systems in Iranian financial-credit institutions in the private sector with regard to the use of human resources needed for different financial operations, given the current context, circumstances, and limitations.

- The employment of operational auditing has a significant influence on maximizing defined (standard) economic savings by managers of financial systems in Iranian financial-credit institutions in the private sector with regard to the use of financial resources needed for different financial operations, given the current context, circumstances, and limitations.

- The employment of operational auditing has a significant influence on maximizing defined (standard) economic savings by managers of financial systems in Iranian financial-credit institutions in the private sector with regard to the use of equipment needed for different financial operations, given the current context, circumstances, and limitations.

\section{Discussion and conclusion}

Operational auditing is an effective tool that offers services and guidance for the management of all financial-credit institutions so it satisfactorily encompasses nearly all auditing features of financial statements. Operation auditing involves the systematic review of the financial activities or parts of such activities within an organization to achieve specific objectives.

To put it another way, operational auditing is an effective approach that has strongly changed the traditional thinking associated with the management accounting. This method has considerable advantages that can be used to control financial operations of various financial-credit institutions 
(banks), making efficient plans in the future, facilitating more efficient, accurate, and precise management decisions, and performing more accurate assessment of managers' financial operations.

Implications of the study

\section{A: Recommendations based on research findings for organizations/banks under study:}

The main point that taken into account concerning the adoption of the operational auditing is that the full access to the advantages of this method is not possible without considering the behavioral factors. The most important behavioral structures needed for the development and successful implementation of operational auditing are:

1. Proper training of all personnel who will be somehow involved in this method,

2. Creating an organizational culture for the adoption of operational auditing,

3. Developing an efficient statistical system to accurately determine and record all information relevant to the organization's financial operations.

\section{B: Suggestions for future researchers:}

1. Based on the findings of the study it is recommended that a comprehensive and integrated operational planning system is developed scientifically in the public sector banks to control financial operations, to follow up, and to inspect resource needed or used in various parts of the system.

2. It is recommended to perform feasibility studies and to examine operational requirements, advantages, and disadvantages of the possibility of using operational auditing in financialcredit institutions (banks) affiliated to the public sector.

3. Finally, it is suggested that the indicators used in this study be studied carefully by the future research to show their associations with economic saving in the institutions under study based on the theoretical and experimental grounds.

\section{References}

Azar, A., \& Momeni, M. (2002). Statistics and its Applications in Management. Tehran University: SAMT Publications (In Farsi).

Arbab Soleimani, A., \& Nafari, M. (2003). Accounting Principles. Volume I (12th edition), Centre for Community Research: Accounting and Auditing Organization (In Farsi).

Alvani, S.M. (2002). Public Management (17th edition). Tehran: Ghazal Press (In Farsi).

Operational Auditing Committee of the Audit Organization. (2001). An introduction to operational auditing. Quarterly of Auditors, 3(10).

Report of Operational Auditing Committee of USA Certified Accountants' Association Management. (2006). Operational auditing: efficiency, effectiveness, economic saving.

Supreme Audit Court. (2008). Guidelines for the implementation of performance auditing standards. $1^{\text {st }}$ ed.

Supreme Audit Court. (2009). Performance auditing and its reporting framework. The Supreme Audit Court: Technical and Auditing Deputy of Ministries and Public Institutions. 